Reacciones y oposiciones en escuelas secundarias del Área metropolitana de Buenos Aires. PÁginas 169-186

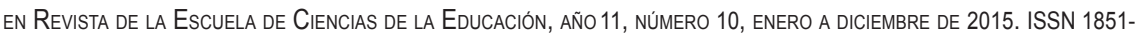
6297. ISSN EN LINEA 2362-3349.

\title{
REACCIONES Y OPOSICIONES EN ESCUELAS SECUNDARIAS DEL ÁREA METROPOLITANA DE BUENOS AIRES
}

\author{
Por Eduardo Langer* \\ Universidad Nacional de General San Martín - CONICET, Argentina. \\ langereduardo@gmail.com
}

\section{Resumen}

En este artículo se caracterizan las reacciones y oposiciones de estudiantes en escuelas secundarias en contextos de pobreza urbana del área de la región metropolitana de Buenos Aires, en un marco en el que los actuales sistemas de regulación y las formas de sancionar las conductas en las instituciones se flexibilizan. Ello se realiza, fundamentalmente, en términos de la sanción y control del tiempo, del espacio, de la tarea, de la actividad escolar y más, específicamente, respecto de las formas de relación con los adultos. Partimos del supuesto que las situaciones cotidianas y los modos de vida de los estudiantes en contextos de pobreza urbana se tensionan con las dinámicas escolares porque, de hecho, esas reacciones y oposiciones implican "un devenir que abre un proceso de creación, de transformación de la situación”. (Lazzarato, 2006: 50).

\section{Palabras Clave:}

Reacciones - Oposiciones - Estudiantes - Contextos de pobreza urbana.

\section{Abstract}

In this article characterized the reactions and oppositions of secondary school students in the context of urban poverty in the metropolitan area of Buenos Aires, in a frame in which the current regulatory systems and ways to punish conduct in the institutions are relaxed. This is mainly done in terms of the sanction and control of time, space, school activity and more specifically on ways of relationships with adults. We assume that everyday situations and lifestyles of students in the context of urban poverty are stressed with school dynamics because, in fact, these reactions and

* Doctor en la Universidad de Buenos Aires con mención en Educación. Licenciado en Ciencias de la Educación por la Facultad de Filosofía y Letras de la Universidad de Buenos Aires y Magister en Ciencias Sociales con mención en Educación por la FLACSO/ Argentina. Actualmente es becario Postdoctoral por el CONICET y se desempeña como Profesor de Sociología de la Educación por la Universidad Nacional de General San Martín y la Universidad Nacional de la Patagonia Austral. 
Revista de la Escuela de Ciencias de la Educación, año 11, número 10, enero a diciembre de 2015. Páginas 169-186. ISSN 1851-6297. ISSN EN LINEA 2362-3349. REACCIONES Y OPOSICIONES EN ESCUELAS SECUNDARIAS DEL ÁREA METROPOLITANA de Buenos Aires. Eduardo Langer

oppositions involving "a future that opens a creative process of transformation situation" (Lazarrato, 2006: 50).

\section{Keywords:}

Reactions - Oppositions - Students - Contexts of urban poverty.

En este artículo se caracterizan las reacciones y oposiciones de los estudiantes ante determinadas formas de regular las conductas que se producen en escuelas secundarias en contextos de pobreza urbana del área de la región metropolitana de Buenos Aires. Específicamente, nos referimos a escuelas de la localidad de José León Suárez, partido de San Martín, que están próximas o dentro de villas miseria y/o asentamientos precarios (1) muy densamente poblados y a estudiantes que son parte de esa población y viven en esas condiciones de pobreza (Langer, 2014).

Se realiza esa descripción en términos, fundamentalmente, de la sanción y control del tiempo, del espacio, de la tarea, de la actividad escolar y más, específicamente, respecto de las formas de relación con los docentes, en un marco en el que las actuales formas de sancionar en las instituciones se flexibilizan. Para ello, se retoman notas de campo realizadas desde 2011 a 2013 utilizando una metodología cualitativa de tipo exploratoria mediante entrevistas en profundidad a estudiantes -individuales y grupales-así cómo observaciones de clases y de otros espacios en escuelas de José León Suárez.

Partimos del supuesto que las situaciones cotidianas y los modos de vida de los estudiantes en contextos de pobreza urbana se tensionan con las dinámicas escolares porque, de hecho, esas reacciones y oposiciones implican "un devenir que abre un proceso de creación, de transformación de la situación" (Lazzarato, 2006: 50). De esta forma, se trata de caracterizar los dispositivos pedagógicos (Grinberg, 2008) desde una perspectiva foucaultiana que supone preguntarse por las formas que asumen las regulaciones de las conductas, por tanto el gobierno, como una actividad más o menos racional y calculada que involucra una variedad de técnicas y formas de saberes procurando modelar las conductas y actuando sobre los deseos, aspiraciones, intereses y creencias hacia objetivos definidos pero, también, cambiantes (Dean, 1999). Aquí se piensa a las escuelas y a los sujetos que allí están en torno a voluntades de poder donde hay fuerzas que se ejercen cotidianamente en un mapa complejo de acción y reacción.

Para ello, en un primer momento se trabajará sobre el concepto de regulación de las conductas en las escuelas del siglo XXI y sobre las tensiones que se producen en las sociedades de control (Deleuze, 1995) a partir del análisis de cómo para los estudiantes las normas se flexibilizan y son discutibles en las escuelas a las que concurren. En un segundo momento, se presentan 
Revista de la Escuela de Ciencias de la Educación, año 11, número 10, enero a diciembre de 2015. Páginas 169-186. ISSN 1851-6297. ISSN EN LINEA 2362-3349. REACCIONES Y OPOSICIONES EN ESCUELAS SECUNDARIAS DEL ÁREA METROPOLITANA de Buenos Aires. Eduardo Langer

las reacciones y oposiciones de los estudiantes a esas formas de regulación haciendo especial hincapié en la reestructuración de las voluntades y de las relaciones de poder entre estudiantes y docentes en el aula. Finalmente, se retoman algunas reflexiones finales sobre aquello que significan e implican las reacciones y oposiciones en estos territorios.

\section{Las tensiones en la regulación de las conductas en el siglo XXI}

Los procesos de regulación implican relaciones de poder y de control ya que se trata de "instalar mecanismos de seguridad alrededor de ese carácter aleatorio que es inherente a una población de seres vivos" (Foucault, 2000: 223). Es decir, Foucault utilizó la palabra regulación, tal como dice Caruso (2005), sólo en vinculación con la biopolítica. De hecho, el objetivo de la regulación para Foucault es "fomentar y dirigir al mismo tiempo los procesos de crecimiento" (Caruso, 2005, p. 59) e involucra una sucesión de "tecnologías de gobierno" (Foucault, 2000). Ahora bien, esos procesos de regulación implican, también, las reacciones y/o resistencias a esas relaciones de poder y control, porque ellas son parte de esas relaciones de fuerza.

En este marco, el estudio de los dispositivos pedagógicos involucra caracterizar el control, la regulación y las reacciones u oposiciones entre sujetos que se relacionan en el espacio escolar y en un contexto que ya no es el de sociedades industrializadas. En otras palabras, cabe preguntarse cuál es el objetivo de las formas de regulación en un marco en el que las sociedades industrializadas se van transformando en sociedades desindustrializadas y flexibles y en el que, también, las formas escolares sufren modificaciones y reformas acordes a los tiempos actuales. A la vez, se trata de interrogarse por las especificidades de las regulaciones en los contextos de pobreza urbana porque son esas modificaciones y tensiones en las formas de regular las conductas en el siglo $\mathrm{XXI}$ que nos encontramos en la vida escolar y sobre las que nos ocupamos brevemente en este apartado, con la finalidad de pensar las reacciones que se producen.

Si hasta fines del siglo XX regular la conducta en la escuela suponía normalizar, poner en estado de normalidad, hacia el presente esto entra en tensión. En tiempos que nos ubican ante procesos de cambio, la regulación de las conductas en la escuela cobra otros sentidos. En el desarrollo del trabajo de campo, observamos diversidad de situaciones respecto de la sanción de las conductas, observamos que cada docente hace lo que puede ante las situaciones que se presentan en el aula: 1 . Unos siguen sancionando como se hacía hace algunos años; 2 . Otros se adaptan a los nuevos requerimientos normativos; 3. Finalmente, otros intentan combinar ambos procedimientos. Esta, quizás, sea la tensión central que surge para regular las conductas y una de las características centrales de las escuelas hoy: ya nadie dice cómo hay que hacer las cosas sino que cada uno las tiene que hacer como cree que 
Revista de la Escuela de Ciencias de la Educación, año 11, número 10, enero a diciembre de 2015. Páginas 169-186. ISSN 1851-6297. ISSN EN LINEA 2362-3349. REACCIONES Y OPOSICIONES EN ESCUELAS SECUNDARIAS DEL ÁREA METROPOLITANA de Buenos Aires. Eduardo Langer

es mejor. Así, los estudiantes se encuentran en las aulas con docentes que procuran diferentes formas de comportarse en el aula o que permiten más o menos determinadas conductas, se hallan constantemente con contradictorios mensajes, tal como decía un docente:

No podes mantener un orden porque primero el de arriba no lo establece, y si no lo establecen arriba vos por ahí tenés las últimas dos horas donde el pibe estuvo todo el día con el mp3 puesto. (...) Pero bueno, es importante que la escuela desde arriba trabaje para que después el lineamiento sea importante porque sino trabajás, trabajás y después te encontrás con que vos le decís al pibe que no use gorrita porque no se puede entrar y después resulta que la otra en el otro grupo la usa. Es todo un doble mensaje que no te sirve porque lo volvés loco, vos le decís sacate, sacate, sacate y el otro no (Entrevista a docente, Escuela Secundaria - José León Suárez, 18 de mayo de 2011).

No se puede mantener un único orden porque no hay lineamientos claros y precisos o, como dice la docente, "el de arriba no lo establece". Esas diferentes formas que los docentes establecen para sancionar entran en tensión y ello "es todo un doble mensaje". Lo central es que la responsabilidad de ese orden recae en el docente porque ya no se trata del castigo, ya no se trata de imponer normas, sino que cada joven comprenda e identifique sus propias normas, "en una sociedad que asume y propone la carencia de normas universales para la regulación de la vida" (Grinberg, 2008, p. 228). Ya no se trata de ser un docente "autoritario", de que "no vuele ni una mosca en el aula" o de tener "fuertes rasgos que marcan la disciplina". Y estas lógicas en la escuela se vuelven confusión para docentes y estudiantes porque "los volvés locos". Más adelante se sostendrá que los estudiantes reaccionan ante esas formas de regular las conductas, ante esas contradicciones que no los convencen o que, muchas veces, les parecen injustas. Además, aquello que sucede, principalmente, es que ante el no saber qué y cómo hacer, muchas veces, son los estudiantes quienes muestran caminos posibles.

Así, las escuelas se encuentran en la encrucijada de cómo sancionar las conductas como, por ejemplo, suspender a algún estudiante y no poder hacerlo porque se tienen que enfrentar con el marco normativo actual. Se produce un marco en el que ya no se sabe muy bien qué sancionar y cómo orientar la sanción en la escuela porque no se puede realizar formalmente o porque se sanciona informalmente, incluso, a veces, al azar, tal como dice un estudiante:

"Sinceramente, te sancionan cuando quieren y depende el humor que tengan. Una vez me sancionaron por traer una mesa porque el curso estaba lleno, así que imagináte" (Entrevista a estudiante, Varón, 16 años, 13 de Junio de 2011). 
Revista de la Escuela de Ciencias de la Educación, año 11, número 10, enero a diciembre de 2015. Páginas 169-186. ISSN 1851-6297. ISSN EN LINEA 2362-3349. REACCIONES Y OPOSICIONES EN ESCUELAS SECUNDARIAS DEL ÁREA METROPOLITANA de Buenos Aires. Eduardo Langer

Si la sanción aparecía hace más de tres décadas como un mecanismo regulador, un conglomerado de prácticas dispuestas para controlar a los cuerpos, se aplicaba ante una infracción de la regla del juego que era impuesta y funcionaba para producir una voluntad normalizada, hoy ocurre algo así como una tensión entre el no poder sancionar formalmente y el sancionar cuando se quiere, tal como dice el relato del estudiante. Si no hay un modelo claro de regulación de conductas y si queda librado a la propia visión del docente qué hacer ante determinadas situaciones, entonces los estudiantes son los que ven esas contradicciones con las que, muchas veces, se manejan arbitrariamente en sus escuelas. En general, nos encontramos con estudiantes que diferencian el respeto o no de las reglas en función de qué norma sea, tal como se expresa en el siguiente registro:

Entrevistador: "ustedes dijeron que no respetan algunas normas...". Karen: "algunas. Las que son tipo...". Ivana: "chiquititas". Karen: "sí, no usar el celular, no comer. No esas que son de gritar al profesor o faltarle el respeto, esas respetamos" (Entrevista grupal a estudiantes, Cuarto año, 30 de Junio de 2011).

Quizás, no se trata de un cuestionamiento de las reglas o de su existencia porque, como dice Kessler (2002), hay un reconocimiento de su valor para el proceso de formación personal o para la construcción del propio destino. Muchas veces, los estudiantes objetan la falta de transparencia y arbitrariedad. Pero, en general, sucede que ante el desconcierto que reina sobre qué es lo que la escuela tiene o no tiene que sancionar, los estudiantes se van autorregulando frente a esas diferentes y confusas situaciones que se presentan en el aula y en la escuela en general. Asimismo, la pregunta por las reacciones y oposiciones frente a esas arbitrariedades y/o confusiones de las reglas que se van estableciendo en la escuela se sitúa, también, frente al "cinismo de un relato que reclama el desarrollo de capacidades para enfrentar las propias situaciones de marginalidad y de expulsión. (...) arrojado a la suerte de mis propias capacidades" (Grinberg, 2008, p. 229).

Se afirman acciones y prácticas en las escuelas que rechazan un tipo de gobierno y aseveran rasgos propios reivindicando la vida entendida como necesidades fundamentales, "el derecho a la vida, al cuerpo, a la salud, a la felicidad, a la satisfacción de las necesidades, el derecho (...) a encontrar lo que uno es y todo lo que uno puede ser" (Foucault, 2008: 137). En este sentido, hay justificaciones de estudiantes que no respetan una regla como defensa de un derecho:

"Por ejemplo con la de geografía. Yo tenía un buzo puesto hasta acá, hasta la nariz porque tenía frío. Dejó la puerta abierta y tenía frío. [Representa la conversación con la docente]. "Bajáte eso", me dice. "Tengo frío". "Pero yo te dije que te lo bajes". Pero si yo tengo 
Revista de la Escuela de Ciencias de la Educación, año 11, número 10, enero a diciembre de 2015. Páginas 169-186. ISSN 1851-6297. ISSN EN LINEA 2362-3349. REACCIONES Y OPOSICIONES EN ESCUELAS SECUNDARIAS DEL ÁREA METROPOLITANA de Buenos Aires. Eduardo Langer

frío no le voy a hacer caso. Si usted quiere ser respetado, tiene que respetar. Ella también tiene que cumplir sus normas. De tratarnos bien. Yo no digo ahhh mira. Pero tratarnos bien. Nosotros también tenemos derechos afuera" (Entrevista grupal a estudiantes, Mujeres, Cuarto año, 30 de Junio de 2011).

El no respeto de una regla por parte de un estudiante tiene como causa, valga la redundancia, el no respeto de un adulto hacia él o ella. Seguramente, también, tiene una asociación fuerte con todos los sinsentidos que se generan en una escuela que si bien perdió su carácter sagrado (Dubet, 2003) no así su legitimidad y valor para esta población. De hecho, la estudiante no respeta la norma no porque sí, sino porque no la respetan a ella, tal como dice "si usted quiere ser respetado, tiene que respetar". Justamente, con la falta de respeto no se le concede reconocimiento a una persona, como dice Sennett (2009), "simplemente no se la ve como un ser humano integral cuya presencia importa" (p.17). Entonces, tratarse bien mutuamente implica la posibilidad de que los estudiantes puedan cumplir y respetar las normas, tratarse mal involucra la posibilidad de que los estudiantes puedan reaccionar. De hecho, la estudiante finaliza diciendo que tienen "derechos afuera". Los derechos que tienen fuera de la escuela valen, también, para cuando están dentro y posibilitan que puedan responder a eso que viven como faltas de respeto en cuanto a sus acciones y comportamientos dentro del aula:

"Hay profesores que gritan, que le faltan el respeto a sus alumnos así. Y la verdad que eso está mal, no vendría eh, mal, un poco de rebeldía de los alumnos. Pero por lo general, ese tipo de violencia de los profesores hacia los alumnos se da en los cursos más chicos, (...) no son de enfrentar, enfrentar realmente, encarar el problema con el director y el profesor que le faltó el respeto. (...) es casi un abuso porque un pibito de doce años por ahí tiene conocimiento de ponerle plasticola en el asiento de la profesora pero no para quejarse, para mostrar su queja, decir que él no puede estudiar, no puede tener un conocimiento si la profesora lo está atacando así. No se puede dictar una clase asi" (Entrevista a estudiante, Varón, 17 años, 2 de octubre de 2012).

Ante docentes que gritan, no viene mal un poco de rebeldía, dice el estudiante. Pero diferencia la rebeldía que puede tener un estudiante de primer año respecto de uno más grande porque con los más jóvenes se ejerce un tipo de violencia y abuso al que no pueden responder, no pueden quejarse y manifestar su reclamo o su defensa para poder estudiar. En este sentido, pensamos que el orden requerido para enseñar a un grupo no se establece de una vez al comienzo de la clase sino que es resultado de un esfuerzo continuo ya que a cualquier docente de pronto el grupo "se le va de las manos", se les "sale de 
Revista de la Escuela de Ciencias de la Educación, año 11, número 10, enero a diciembre de 2015. Páginas 169-186. ISSN 1851-6297. ISSN EN LINEA 2362-3349. REACCIONES Y OPOSICIONES EN ESCUELAS SECUNDARIAS DEL ÁREA METROPOLITANA de Buenos Aires. Eduardo Langer

control" y los estudiantes "subvierten el orden" (Rockwell, 2006, p. 10). Esas reacciones y oposiciones que expresan los estudiantes son, muchas veces, como indica el registro para poder tener clase y para tener un conocimiento sin que se los esté atacando a los estudiantes. Ellos enfrentan, no aceptan órdenes porque sí y, como dice Grinberg (2009), este tipo de situaciones de enfrentamiento ofuscado dependen de las reacciones de los sujetos que pueden, en el devenir de la clase, quedar en el olvido o provocar una espinosa discusión, tal como desarrollaremos a continuación.

\section{Las formas que adoptan las reacciones y las oposiciones estudiantiles en contextos de pobreza urbana}

Un modo de acercarse a las prácticas de los estudiantes ligadas con las reacciones y oposiciones ante las formas de regular las conductas en las escuelas, es pensar sobre los modos en que la negación por la vida de los sujetos, muchas veces, es aquello que caracteriza la cotidianeidad barrial.

Si la vida toma un valor de nada, nihilismo (Deleuze, 1986), que pesa y estigmatiza a los sujetos en contextos de pobreza urbana, también, significa reacción contra el mundo y pesimismo de la debilidad que "halla su principio simplemente en la vida reactiva, en las fuerzas reactivas" (Deleuze, 1986, p. 208). Es un nihilismo reactivo. Así, referir a las reacciones, implica pensar en torno a las voluntades de poder donde hay fuerzas dominantes o superiores a las que Nietzsche las llama "activas" y hay fuerzas inferiores o dominadas a las que llama "reactivas", donde habrá una jerarquía con respecto a la diferencia de esas fuerzas. Aquí se construye un punto de partida para pensar las reacciones como un tipo de fuerzas del mismo modo que la acción, fuerzas en relación con lo activo y lo dominante.

Si toda conducta está dictada por un interés que causa la actividad de algunas reacciones en un momento dado, es decir "hacemos eso porque nos interesa" (Clapárede, 1932, p. 71), entonces "los sujetos pueden reaccionar de múltiples maneras en un campo múltiple de posibilidades" (Perea Acevedo, 2009 , p. 19). Tanto estudiantes como docentes se relacionan en un campo en el cual pueden desenvolverse varias formas de conducta, varias reacciones y diversos comportamientos (Foucault, 1988, p. 15). Justamente, no todas las prácticas son iguales porque, retomando a Foucault (1988), sólo se puede ejercer el poder sobre otros porque éstos son quienes con sus reacciones y posibilidades dinamizan e impulsan el ejercicio. De hecho, desde las miradas de los adultos se asocia la rebeldía a aquellas reacciones que los estudiantes tienen cuando alguien trata de imponer algo, tal como dice una autoridad escolar:

"En este contexto, el estudiante rebelde es aquel que uno le impone algo y no quiere que le impongan nada. Y sobre todo, que no le griten, que no le griten. Yo pienso que es porque están acostumbrados 
Revista de la Escuela de Ciencias de la Educación, año 11, número 10, enero a diciembre de 2015. Páginas 169-186. ISSN 1851-6297. ISSN EN LINEA 2362-3349. REACCIONES Y OPOSICIONES EN ESCUELAS SECUNDARIAS DEL ÁREA METROPOLITANA de Buenos Aires. Eduardo Langer

a que les griten. Ante el grito reaccionan de la misma manera que en su casa o en el barrio ¿no? Vuelven a gritar más, a levantarse e irse de un portazo. O contestar, insultar al profesor, patear sillas" (Registro de entrevista a vicedirectora, Escuela de José León Suárez, 11 de Octubre de 2012).

Los estudiantes reaccionan cuando les gritan, contestan y no se quedan callados, tal como vamos a desarrollar más adelante. Si bien los estudiantes reaccionan de diferentes maneras -con humor, agresivamente, negociando, objetando, defendiéndose- no sólo lo hacen para obtener concesiones, sino como formas de sobrevivir y hacer frente a las formas de negación de sus propias vidas, hacer frente al valor de nada que, muchas veces, se les otorga a sus vidas. Por ello, las reacciones de los estudiantes tienen que ver con sus situaciones de vida y con razones muy profundas. Así, es necesario distinguir las diferentes reacciones que tienen los estudiantes en esos contextos históricos $\mathrm{y}$, fundamentalmente, contra qué clase de injusticias reaccionan, tal como se expresa en el siguiente registro de entrevista:

"Cambiar algo que está ya preestablecido o que nosotros creemos que es así, y en algún momento llega una ruptura o un cuestionamiento de ese hecho permanente que se da en los cursos. Y cuando llega esta ruptura se denomina como rebeldía. Por ejemplo, cuando un alumno le grita a un profesor que no le falte al respeto, que no lo exija de más, que no lo presione porque no entiende, porque tiene problemas en su casa, porque se siente mal, porque ese día simplemente no es el día de uno. Es cambiar algo que todos creemos que es así, que está preestablecido y que hay una ruptura, un cuestionamiento, una opinión fuerte y decisiva, una... como una oposición a eso. (...) Pasa que, muchas veces, algunos profesores piensan que todos venimos de la misma casa. Todos tenemos nuestras vidas, todos tenemos nuestra cotidianeidad, nuestra vida cotidiana y para todos es diferente, todos tenemos situaciones diferentes, todos manejamos un nivel de economía totalmente diferente" (Entrevista a estudiante, varón, 17 años, 2 de octubre de 2012).

Se reacciona para, como señala el estudiante, "cambiar algo que está preestablecido". Al menos en la institución escolar es cuestionar lo instituido. Y acá es donde la reacción toma forma de una oposición a manera de ser conducido en la que no se acuerda, en la que hay motivos para no acordar porque tienen problemas en sus casas, porque se sienten mal, porque no es el día indicado, porque "todos tenemos situaciones diferentes" que indican cómo los docentes llegan a dar clases y cómo los estudiantes llegan a estudiar. La reacción posibilita, para el estudiante, no sólo un cuestionamiento o una oposición frente a una forma de regular la conducta en la escuela sino que implica un 
Revista de la Escuela de Ciencias de la Educación, año 11, número 10, enero a diciembre de 2015. Páginas 169-186. ISSN 1851-6297. ISSN EN LINEA 2362-3349. REACCIONES Y OPOSICIONES EN ESCUELAS SECUNDARIAS DEL ÁREA METROPOLITANA de Buenos Aires. Eduardo Langer

cambio, una forma diferente de estar allí, seguramente, mejor. Son reacciones que les permiten pensar en transformar aquellas cosas con las que no están conformes, frente al mundo que viven. Son modos que implican defensa y pedidos de que las cosas sean de distinta forma ejerciendo derechos.

En este sentido, diferenciar la oposición de "hacer lío" nos puede ayudar porque, tal como nos decía un directivo, algunos estudiantes se vuelven "demonios de Tasmania" que simplemente, vuelven locos a todos y en cada lugar que están. Los demonios de Tasmania son, según las palabras del director, los que hacen lío en toda hora en la escuela. Aquí, desde ya que no se trata de estudiantes que son "demonios de Tasmania" por naturaleza sino que hay un marco en el que desarrollan sus acciones. Al cambiar ese contexto, el estudiante, también, lo hace, "se adapta al nuevo contexto". Pero hay diferencia entre ese "volver loco a todo el mundo" con la oposición a la autoridad porque, tal como dice el siguiente estudiante, la oposición tiene sus motivos o sus causas que hay que buscarlas en "la clase de vida":

"O capaz que no es porque no le hace caso a los profesores ni a la madre, capaz porque en la casa no les importa lo que haga y él se porta así. Capaz que decide portarse como rebelde o portarse bien. Eso depende de él. Eso es la clase de vida" (Entrevista grupal con estudiantes, Mixta, Quinto Año, Mayo 2012).

Para los estudiantes en contextos de pobreza urbana la rebeldía es no hacerle caso a la profesora. Es la negación u oposición a la autoridad como una forma de conducción y regulación de la conducta, sea en la escuela o en la familia. Es una decisión a partir de aquello que sucede en sus casas, de aquello que sucede en las escuelas. Depende de "la clase de vida" tanto como de las dinámicas que se establecen. Por ello, los estudiantes pueden portarse como rebeldes o portarse bien, porque pueden ver aquello que sucede a su alrededor. Si bien los estudiantes pueden asociar la rebeldía como oposición, a las capacidades que tienen para negarse a aprender aquello que los docentes les proponen (Erickson, 1984), también, pueden ser prácticas para reclamar derechos o defenderse. Los estudiantes perciben las falencias de las escuelas y las debilidades de los docentes y, muchas veces, las utilizan para descontrolar una clase pero, otras veces, las utilizan para saber qué es lo que hay que pedir, demandar o, simplemente, aquello que les gustaría cambiar del aula. Incluso esa "debilidad" de la autoridad se presenta como un problema y, entonces, devienen en oposiciones estudiantiles ante una autoridad que no puede imponerse en un contexto de flexibilización de las sanciones. No hacen caso en un contexto en el que el "poder hacer nada" (Langer, 2014) es la regla.

Entonces, la pregunta en torno de las reacciones y oposiciones de los estudiantes en contextos de pobreza urbana procura comprender aquello que hacen en la escuela y las formas en que lo hacen, comprender las acciones en 
Revista de la Escuela de Ciencias de la Educación, año 11, número 10, enero a diciembre de 2015. Páginas 169-186. ISSN 1851-6297. ISSN EN LINEA 2362-3349. REACCIONES Y OPOSICIONES EN ESCUELAS SECUNDARIAS DEL ÁREA METROPOLITANA de Buenos Aires. Eduardo Langer

las instituciones a partir de los modos que adquieren sus vidas en esos contextos. Se trata de describir a una heterogeneidad de "prácticas que se agrupan y desagrupan en microdisidencias comunitarias, en las que caben distintas formas de respuesta y actitudes frente al poder" (Reguillo, 2012, p.47). Por ello, cuando hacemos referencia a las reacciones y oposiciones en la escuela, estamos pensando en la interacción que se establece entre los modos de regulación de las conductas que las escuelas producen y aquello que hacen o cómo responden los estudiantes ante esas formas; es decir, cómo los estudiantes actúan ante una situación, un docente, una actividad, una nota, una evaluación, un acto o algo que, simplemente, les dicen. En palabras de un director:

"Te pongo el ejemplo a partir de una situación escolar que se dio en un acto escolar. Estaba buscando dos estudiantes para que icen la bandera. Iba preguntando por las filas quién quería hacerlo. Un estudiante que estaba en una fila me dice "¿por qué no la iza usted?? Yo le dije que con mucho gusto lo hacía y fui a izarla. Los chicos quedaron descolocados, no entendían. Lo mismo que los profesores. Los chicos pensaban que no iba a reaccionar así, que iba a reaccionar de otra forma. Fue una provocación lo que hizo ese estudiante y yo no reaccioné y se sorprendieron. Algunos docentes también se sorprendieron y me dijeron cómo voy a dejar que me traten así. Descoloqué a los estudiantes porque icé la bandera y no reaccioné de la manera que ellos pensaron. De hecho no tiene sentido reaccionar ante esas cosas" (Registro de campo, diálogo informal con director de escuela, José León Suárez, 2 de Junio de 2011).

Ante una pregunta de un adulto en la escuela hay una reacción de un estudiante que hace una pregunta en forma de contestación, “¿por qué no la iza usted?". Pero esa reacción puede ser o no contestación u oposición dependiendo de cómo se desarrollen las interacciones entre los sujetos. Como señala luego el director, quizás algunos de los docentes hubiesen hecho otra cosa con esa provocación del estudiante, quizás hubiesen reaccionado en torno al objetivo central de imponer una orden en el espacio escolar, pero es la autoridad la que descoloca a docentes y estudiantes en esa interacción, simplemente yendo él a izar esa bandera. Ante la reacción del estudiante, hay estrategia y posibilidad pedagógica de mostrar otras formas posibles de hacer escuela.

Importa aquí, recuperar la relación entre la reacción y la oposición a partir de los procesos de reestructuración de las voluntades y las relaciones de poder porque, justamente, la relación pedagógica se piensa como encuentros entre voluntades que se afirman en su diferencia (Deleuze, 1986), siempre imprevisibles, impredecibles, abiertas y arriesgadas. Son voluntades que expresan relación de fuerzas, por tanto, "voluntad de poderío" (Nietszche, 1980) y suele manifestarse cuando encuentra resistencia que "por definición no pueden existir 
Revista de la Escuela de Ciencias de la Educación, año 11, número 10, enero a diciembre de 2015. Páginas 169-186. ISSN 1851-6297. ISSN EN LINEA 2362-3349. REACCIONES Y OPOSICIONES EN ESCUELAS SECUNDARIAS DEL ÁREA METROPOLITANA de Buenos Aires. Eduardo Langer

sino en el campo estratégico de las relaciones de poder" (Foucault, 2008, p. 92). Por tanto, plantear la "cuestión de la voluntad" (Foucault, 2006) en este momento es central para entender las características que adquieren las reacciones y oposiciones de estudiantes en contextos de pobreza urbana. Si la resistencia es la fuerza que se opone a otra fuerza que se considera activa entonces "la voluntad es la fuerza" (Foucault, 2012, p. 97), es una fuerza que se halla en una relación esencial con otra fuerza. Por ello, la fuerza se llama voluntad y ésta "es el elemento diferencial de la fuerza. (...) Una voluntad actúa sobre otra voluntad" (Deleuze, 1986, p.15). El problema central es "¿Qué quiere una voluntad?" (Deleuze, 1986, p.18). Precisamente, la educación es la dirección de la voluntad ante los flujos no codificados de quienes llegan al mundo y así "la tarea educativa se realiza en una acción que supone la relación entre dos voluntades/fuerzas" (Grinberg, 2008, p.34). Por tanto, la pedagogía, es un territorio que se configura como campo de relación de fuerzas y encuentro de voluntades. En este marco nos preguntamos cómo se producen esas expresiones de fuerzas, voluntades y relaciones entre estudiantes y adultos de las escuelas en contextos de pobreza urbana teniendo presente que aquello que denominamos fuerzas activas o dominantes no es el mal y esas fuerzas reactivas son el bien, sino que el problema es que son juegos estratégicos, tal como lo dice Foucault (1988), en los que los efectos de dominación "pueden llevar a que un niño sea sometido a la autoridad arbitraria e inútil de un maestro, o a que un estudiante esté bajo la férula de un profesor abusivamente autoritario" (p. 115).

Es aquí donde adquiere importancia caracterizar las reacciones y las prácticas de oposición cotidianas de los estudiantes ante los mecanismos de un orden establecido al que ellos perciben como injusto y en un contexto en el que las instituciones y los docentes están cada vez más solos y librados a su propia suerte (Grinberg, 2008). Es en este contexto que nos preguntamos cómo esas prácticas de reestructuración de las relaciones y voluntades en el aula son, muchas veces, para tener una clase en un marco en el que los estudiantes se defienden y no se callan ante regulaciones que no les parecen justas, tal como se desarrolla a continuación.

\section{“¿Quién sos?” y “¿Qué se piensa que soy?”: estudiantes que se defienden y no se callan.}

Frente a humillaciones $u$ otro tipo de situaciones que suponen maltrato en la escuela, los estudiantes se defienden y luchan por aquello que creen que no corresponde como, por ejemplo, que no les pongan una nota o no les saquen el cuaderno de comunicados, que no les digan que no entregaron una tarea o actividad cuando ya lo hicieron, que les digan a preceptores $u$ otros que no los traten ni les hablen mal, que quieren igualdad de condiciones para ellos y sus docentes en el aula, que les gustaría callar a los docentes, etc. En palabras de un estudiante: 
Revista de la Escuela de Ciencias de la Educación, año 11, número 10, enero a diciembre de 2015. Páginas 169-186. ISSN 1851-6297. ISSN EN LINEA 2362-3349. REACCIONES Y OPOSICIONES EN ESCUELAS SECUNDARIAS DEL ÁREA METROPOLITANA de Buenos Aires. Eduardo Langer

"Sí, a veces que me saca y le contesto. Una vez viste estaba hablando de las mariposas, que todas las mariposas que existen viven un solo día. Yo digo no, que hay mariposas que viven más de un día que viajan de continente a continente [Representa la voz del profesor]. "Deja de hablar pavadas", me grita así re enojado. Pero anda a cagar le digo viejo retrasado mental. Casi lo mato, está re loquito, no se haga el pillo. Encima citó a mi papá y todo un quilombo. ¿Tanto por una cosa que le dije así nomás? Encima que él la empezó a flashear" (Entrevista con estudiante, varón, 14 años, 27 de octubre de 2011).

El estudiante que está participando de la clase reacciona ante una mala contestación del profesor que no sólo le grita sino que le dice que aquello que está diciendo el estudiante es "una pavada" y que, por tanto, no tiene sentido o no sirve directamente. Decirle a un estudiante que no sirve él, lo que dice y/o piensa, tiene sus efectos negativos para el docente que, también, recibe una mala contestación. El que termina "perdiendo", como la mayoría de las veces, es el estudiante, porque llaman a sus padres o porque recibe una mala nota incluso cuando estaba participando. Justamente, en esta situación donde ambos, docente y estudiante, se contestan mal y "se zarpan" se pierde de vista que el estudiante estaba atento, estaba aprendiendo y produciendo algo con el saber en la clase.

Ahora bien, este registro permite preguntarse por otra cuestión que entendemos clave para la descripción de las reacciones y oposiciones: en el presente pareciera que en las aulas ya no estamos ante la pasividad ni el silencio que tradicionalmente se adscribía a los sectores populares (Scott, 2000) sino por el contrario, ante la defensa y la contestación no disimulada, tal como ocurre en el registro anterior y como se observa en el siguiente:

"Una vez yo estaba copiando y le digo "¿cómo dijo? ¿Punto aparte o punto seguido?". "Te dije punto a parte" [representa la voz y el grito de su docente], "bueno no la escuché" [representa cómo le contestó ella gritando a la docente]. Y después seguí hablando con mi compañera. “¿Me estás escuchando?”. Y yo le digo no. Y ahí me pusieron una falta. Me puso un uno. Porque yo le estaba hablando bien. Le pedí, por favor, que me vuelva a repetir. Me contestó mal, yo le respondo mal. Si me sacás, yo respondo. Lo que es el poder, ¿no?”. (Entrevista grupal con cuatro estudiantes, Mujeres, Cuarto año, 30 de Junio de 2011).

Ante el contestar mal se responde peor dice la estudiante. Hay acción y reacción de docentes y estudiantes, respectivamente. Aunque no siempre se configure en ese orden, se vuelven un campo de acción y contestación 
Revista de la Escuela de Ciencias de la Educación, año 11, número 10, enero a diciembre de 2015. Páginas 169-186. ISSN 1851-6297. ISSN EN LINEA 2362-3349. REACCIONES Y OPOSICIONES EN ESCUELAS SECUNDARIAS DEL ÁREA METROPOLITANA de Buenos Aires. Eduardo Langer

relacionado con cómo los estudiantes piden tener los mismos derechos que sus docentes. Ante una pregunta hay un docente que contesta mal y luego una estudiante que se ofende y se defiende respondiendo sin ningún cuidado, con indiferencia y no escuchando más la clase. Es decir, está conectada pero luego del entredicho se desconecta y deja de prestar atención. Como no está escuchando y se lo dice directamente a la docente recibe una mala nota, le pone un uno. Pero no se calla, le responde porque tiene el mismo derecho y a pesar de, tal como reflexiona la estudiante, aquello que hace y produce ese tipo de poder. Contestar mal y poner un uno. Ante ello la estudiante no se calla, hay una reacción, otro poder, una resistencia, se asume la voz para decirle a los profesores que los traten bien. Ello da cuenta de quiénes son los estudiantes hoy en las escuelas en contextos de pobreza urbana y de cómo se acercan al conocimiento y al saber que les propone la escuela. Los estudiantes se animan a defenderse y a cuestionar aunque, nuevamente, aquello que se termina perdiendo, muchas veces, con estas situaciones, es lo que sucede con el saber. No estamos diciendo que no lo hay, sino que no se sabe qué pasa. Es decir, no sólo nos encontramos con estudiantes que se animan a defenderse y cuestionar sino a afirmarse en su propia y diferente identidad, un "nosotros somos diferentes, somos asi", tal como lo expresa el siguiente registro de entrevista:

"La profesora le dijo, lo único que supo decir, se notó muy sorprendida, “QQuién sos vos ahora? ¿La defensora de los pobres?” o algo así. Y la verdad que sí, o sea, no es que nosotros no tenemos voz o los profesores nos tienen que gritar, nos tienen que retar y después explicar y que nosotros entendamos. La chica le dijo que no tiene derecho de tirarle cosas así, de contestar mal y que la manera que explica no está bien para todos, o sea, que sea algo más universal. Y no. Que no es así, o sea todos nosotros somos diferentes, somos así dijo" (Entrevista con estudiante, varón, 17 años, 2 de Octubre de 2012).

Esa estudiante es interpelada con la pregunta “¿Quién sos vos ahora?” y, justamente, la respuesta a la pregunta por el "¿quiénes somos?" (Foucault, 1991, p.60) implica un cierto rechazo a los procesos de violencia cotidiana. La respuesta que da la docente a su propia pregunta, "la defensora de los pobres", es el rechazo de un estudiante a la injusticia y al maltrato de un docente por tirarle un cuaderno de comunicados al piso, por hablarle o contestarle mal. Ser la "defensora de los pobres" es ser de una forma que la escuela y los docentes no están acostumbrados o no estaban acostumbrados cuando los sectores populares no ingresaban a la escuela o, por lo menos, en su gran mayoría no lo hacían. Esas formas de ser tienen que ver, fundamentalmente, con ese no callarse y responder que tienen los estudiantes en estos contextos ante aquello que no creen correcto o que creen injusto, porque ante todo quieren defender 
Revista de la Escuela de Ciencias de la Educación, año 11, número 10, enero a diciembre de 2015. Páginas 169-186. ISSN 1851-6297. ISSN EN LINEA 2362-3349. REACCIONES Y OPOSICIONES EN ESCUELAS SECUNDARIAS DEL ÁREA METROPOLITANA de Buenos Aires. Eduardo Langer

sus derechos. La estudiante, quizás, intenta explicarle a la docente con su reacción cómo son ellos, cómo son los estudiantes que están ahí en el aula, "somos así" y "somos diferentes" a ustedes los adultos, los docentes que "no tienen derecho de tirarles las cosas". Pero ese "¿quién sos?" no sólo aparece desde los discursos de los docentes hacia los alumnos, sino también de los estudiantes hacia los docentes pero en forma un tanto distinta. El "¿quién sos?" de los estudiantes es una defensa y un desafío, tal como se reafirma en otro registro de entrevista:

"Que te hablen, que no te caguen a pedos por cualquier cosa, que no te vengan a atacar, que no te griten, que te hablen bien. A veces tengo unas ganas de meterle un arrebato a la vieja esa. Sacarle los anteojos. Bajarle todos los dientes. Pero me atajo. Nosotros nos mandamos nuestras cagadas pero no es para que nos vengan a atacar, te tienen que decir. Venís de tu casa que tu mamá te caga a pedos, te caga a palos y acá te cagan a pedos. Aguantá, ¿Quién sos? Para eso me quedo en mi casa, que mi mamá nomás me cague a pedos. Tomátela" (Entrevista grupal a estudiantes, Mujeres, Tercer año, 2010).

Hablar sin atacar, hablar sin gritar o hablar bien es lo que pide la estudiante porque ante el ataque o el grito, ella tiene ganas de reaccionar, de "meterle un arrebato" o bien de quedarse en su casa. La estudiante reconoce su lugar como tal en el que se mandan "cagadas" pero eso no justifica los malos tratos y las malas formas contra los estudiantes porque, aún estando acostumbrados a ello, quizás, reclaman y quieren otras cosas. Allí es, nuevamente, que aparece la pregunta por el "¿quién sos?", diferencia que marca el quién es la estudiante, tal como se describía anteriormente, pero, también expresa un desafío a la autoridad por "sacarle los anteojos. Bajarle todos los dientes", es una provocación, justamente, para defender quién es ella. Pero se "ataja". Es una defensa para que no los traten mal y un desafío por ese mal trato. Entonces, los estudiantes no sólo tienen sus propios ritmos, tiempos y espacios, sino que presentan reacciones, -aún, muchas veces, reconociendo lo propio de, como decía el registro anterior, de "mandarse sus cagadas"- ante formas de regular en las escuelas que les parecen indebidas tal como las faltas de respeto 0 , también como nos decían muchos estudiantes, ante determinadas formas de evaluar. Alli hay interpelaciones para que los evalúen "con objetividad", "por lo que da la nota" y "no por el comportamiento", tal como expresa el siguiente registro de observación de una clase.

Nahuel: "¿Qué se piensa que soy? ¿boludo? Vengo todos los días, todo el día". Profesora: "Sos muy desubicado. Yo no te tengo que mostrar nada". Nahuel: "Usted tiene que corregir lo que escribí, no el comportamiento. ¿Por qué yo le tengo que entregar algo que nadie 
Revista de la Escuela de Ciencias de la Educación, año 11, número 10, enero a diciembre de 2015. Páginas 169-186. ISSN 1851-6297. ISSN EN LINEA 2362-3349. REACCIONES Y OPOSICIONES EN ESCUELAS SECUNDARIAS DEL ÁREA METROPOLITANA de Buenos Aires. Eduardo Langer

presentó? Muéstreme quien le presentó eso que me pide. Usted discrimina, la tiene contra los hombres. Todo para las chicas. Así cualquiera. Usted es fascista. Discrimina todo el tiempo". Profesora: "Fascista, sí [lo dice irónicamente]. Nahuel no es un tema de sexo. Analicen con objetividad las cosas". Nahuel: "Usted con objetividad". [Nahuel se va pegando un portazo al aula]. (Registro de observación de clase, Sexto año, 15 de septiembre de 2011).

De forma que los estudiantes reaccionan ante aquellas situaciones que les parecen injustas contestando, defendiéndose y no callándose. También, lo hacen a partir de demandas y cuestionamientos que hacen hacia sus docentes. En este sentido, las reacciones y oposiciones son un no dirigido a los docentes a la vez que un proceso que procura la transformación de situaciones vividas en el aula. El “¿Qué se piensa que soy?” del estudiante reafirma la defensa y el cuestionamiento hacia la docente porque, como dice Nahuel, va "todos los días, todo el día". No es menor y de poca importancia que el estudiante diga que va todos los días y todo el día como defensa cuando las ausencias y las presencias constituyen un problema central en estas escuelas. Le cuestiona a la docente que tiene que corregir con objetividad, sin discriminar, evaluarlo por lo que escribió o por lo que sabe y no por lo que es o por cómo se comporta. Asimismo, nos encontramos frente a otros posicionamientos de los estudiantes que no sólo tienen que ver con las pugnas por las formas de evaluar o por las notas que les pusieron sino, también, que se animan a ordenar la clase ante la desorganización, a corregir a sus docentes -por ejemplo, sus errores de ortografía o las formas de pronunciación-, a decirles que tienen algo mal en la vestimenta o que muestran sus conocimientos con las tecnologías por sobre los del docente ayudando con las dinámicas de la clase con computadoras. Es decir, las reacciones de los estudiantes, también, pueden expresar demandas hacia sus docentes de tener más clases (2) o de ordenar la clase existente, de tener mejores condiciones y más respeto desandando procesos de clasificación. Así como, también, son estudiantes que reconocen todas las dificultades con las que llegan los docentes al aula para enseñar. Los estudiantes consideran que pueden conseguir y apelar a los derechos que ellos tienen en sus relaciones con los docentes en el aula y entre esos derechos se encuentran, seguramente, aquellos que buscan respeto por su persona así como un poco de lógica al aula para que se desarrolle la clase. Para ello no se callan y de alguna forma condenan al silencio que, paradójicamente, condenó a los sectores populares durante mucho tiempo por un modelo de escuela que se impuso en el que el profesor hablaba o transmitía y los alumnos sólo escuchaban. 
Revista de la Escuela de Ciencias de la Educación, año 11, número 10, enero a diciembre de 2015. Páginas 169-186. ISSN 1851-6297. ISSN EN LINEA 2362-3349. REACCIONES Y OPOSICIONES EN ESCUELAS SECUNDARIAS DEL ÁREA METROPOLITANA de Buenos Aires. Eduardo Langer

\section{A modo de corolario...}

La cotidianeidad de los estudiantes y sus reacciones se definen entre el terreno de la desazón y de la posibilidad donde se juegan relaciones de poder, de amor y odio. Esas reacciones expresan que los estudiantes, en general, quieren quedarse en su escuela pero quieren que sea mejor, que haya menos injusticias, que los traten bien, que sea un espacio ameno. Así, "siempre hay algo o algún motivo para ser rebelde" en función de "la clase de vida" que viven en estos contextos.

Son estudiantes que discuten las normas, sean las tradicionales o las novedosas (como los sistemas de convivencia), no porque no les importen mucho (Kessler, 2002) sino porque, justamente, les interesan. En todo caso, lo que no importa son las normas y las sanciones que no se mantienen, cambian constantemente en función de problemas que van surgiendo, se adaptan a las situaciones particulares, se van flexibilizando. Con ello no queremos decir que estamos de acuerdo con un marco más rígido sino que, muchas veces, esos constantes cambios producen el rumbo y la orientación que desorienta tanto a estudiantes como a docentes tanto fuera como dentro del aula.

En este marco quisimos poner en tensión algunos discursos que sostienen que a los estudiantes no les importa la dinámica, una nota, una sanción o un bajo concepto a través de las reacciones y oposiciones que presentan en la escuela y que expresan las formas por las cuáles sí les interesa, se defienden, cuestionan, corrigen y demandan a la escuela, a los docentes, a las autoridades, etc. De forma que la discusión de si a los estudiantes les importan o no las reglas, si son desobedientes o si reaccionan implica dar cuenta de los amores y odios de los estudiantes, de sus propias vidas, qué cuestionan con esas reacciones, cómo se defienden de las situaciones que les parecen injustas, qué demandan a la escuela y a sus docentes, por qué se oponen a un docente con tanto énfasis y con otro establecen estrechos vínculos, de qué hablan o no los estudiantes, qué quieren de la escuela, en el aula y en cada materia en un contexto en el que los estudiantes vivieron y están viviendo situaciones que, a veces, se parecen mucho a un "nada tiene sentido" y "todo da lo mismo", como nos decía un estudiante. Es decir, lo que vivieron y lo que viven, el tipo de infancia y la junta, como las justificaciones para tener determinadas actitudes, de ser o no rebelde. Entonces, las reacciones y oposiciones de los estudiantes en contextos de pobreza urbana tienen motivos y razones profundas que dependen de uno pero, también, dependen de otro u otros. $Y$ si también depende de otros, seguramente, varía que haya alguien o no haya nadie para "ponerte de onda". Aún así los estudiantes quieren llamar la atención de alguna forma, que les presten atención porque ante el "nada tiene sentido" ellos otorgan sentidos y significados, se terminan "asociando con gente" para que, justamente, algo tenga sentido. 
Revista de la Escuela de Ciencias de la Educación, año 11, número 10, enero a diciembre de 2015. Páginas 169-186. ISSN 1851-6297. ISSN EN LINEA 2362-3349. REACCIONES Y OPOSICIONES EN ESCUELAS SECUNDARIAS DEL ÁREA METROPOLITANA de Buenos Aires. Eduardo Langer

Por tanto, aquí pensamos a esas reacciones y oposiciones desde las afirmaciones de los sujetos respecto de lo que vivieron o lo que están viviendo. Aunque pudiera parecer evidente que en toda acción hay una afirmación y en toda reacción hay negación, aquí entendemos que la reacción y oposición no siempre involucra negación porque la acción y la reacción afirman y niegan, requieren de la afirmación y de la negación (Deleuze, 1986). Los estudiantes en contextos de pobreza urbana reaccionan ante las injusticias, se oponen a formas de regular las conductas en las escuelas que no les parecen bien y ello conlleva, siguiendo a Hessel (2006), acciones constructivas, motivadas por el rechazo de la pasividad y de la indiferencia. Es decir, saber decir no, denunciar, protestar frente a lo que no parece legítimo y cercena los derechos pero, también, saber decir sí, actuar y tomar parte a través de sus propias maneras y formas.

\section{Notas Bibliográficas}

(1) Para una definición y caracterización de la noción de villa miseria se puede consultar Ratier (1972).

(2) Por cuestiones espaciales no se desarrolla aquí esta dimensión de análisis. Se puede ver en Langer (2004).

\section{Referencias Bibliográficas}

- Caruso, M. (2005). La biopolítica en las aulas. Prácticas de conducción en las escuelas elementales del Reino de Baviera, Alemania (1869-1919). Buenos Aires: Prometeo Libros.

- $\quad$ Clapárede, E. (1932). La educación funcional. Madrid: Espasa Calpe.

- $\quad$ Dean, M (1999). Governamentality. Power and rule in modern society. London. Sage.

- Deleuze, G. (1986). Nietzsche y la filosofía. España: Anagrama.

- Deleuze, G. (1995). "Post-scriptum sobre las sociedades del control". En Deleuze G. Conversaciones 1972-1990. Valencia: Pre-Textos.

- Dubet, F. (2003). “¿Mutaciones institucionales y/o neoliberalismo?”. En: Tenti Fanfani E., Gobernabilidad de los sistemas educativos en América Latina. Buenos Aires: IIPE.

- $\quad$ Erickson, F. (1984). "School Literacy, Reasoning and Civility".In Review of Educational Research. $\mathrm{N}^{\circ} 54$ (4). Pp. 525-546.

- $\quad$ Foucault, M. (1988). "El sujeto y el poder". En H.L. Dreyfus y P. Rabinow. Michel Foucault: más allá del estructuralismo y la hermenéutica. México: UNAM.

- $\quad$ Foucault, M. (1991). "La Gubernamentalidad". En AA.VV., Espacios de Poder. Madrid: La Piqueta.

- Foucault, M. (2000). Defender la sociedad. Curso en el Collège de France (1975-1976). Buenos Aires: Fondo de Cultura Económica.

- Foucault, M. (2006). Seguridad, territorio, población. Buenos Aires: Fondo de Cultura Económica.

- Foucault, M. (2008). Historia de la sexualidad. 1. La voluntad de saber. Buenos Aires: Siglo veintiuno editores. 
Revista de la Escuela de Ciencias de la Educación, año 11, número 10, enero a diciembre de 2015. Páginas 169-186. ISSN 1851-6297. ISSN EN LINEA 2362-3349. REACCIONES Y OPOSICIONES EN ESCUELAS SECUNDARIAS DEL ÁREA METROPOLITANA de Buenos Aires. Eduardo Langer

- $\quad$ Foucault, M. (2012). El poder, una bestia magnífica. Sobre el poder, la prisión y la vida. Argentina: Siglo Veintiuno editores.

- $\quad$ Grinberg, S. (2008). Educación y poder en el siglo XXI. Gubernamentalidad y pedagogía en las sociedades de gerenciamiento. Buenos Aires: Miño y Dávila.

- $\quad$ Grinberg, S. (2009). "Políticas y territorios de escolarización en contextos de extrema pobreza urbana". En Revista archivos de Ciencias de la Educación, Año 3- №3, UNLP. Pp 81-98.

- $\quad$ Grinberg, S. y Langer, E. (2012). "Education and Governmentality in Degraded Urban Territories: From the Sedimented to the Experience of the Actual". In Surviving economic crises through education. Peter Lang Publishing: Sydney. Pp. 149-164.

- Hessel, S. (2006). Comprometeos. Ya no basta con indignarse. Conversaciones con GillesVanderpooten. Barcelona: Ediciones Destino.

- Kessler G. (2002). La experiencia escolar fragmentada. Estudiantes y docentes en la escuela media en Buenos Aires. Buenos Aires: UNESCO/Instituto Internacional de Planeamiento de la Educación.

- Langer, E. (2014). Dispositivos pedagógicos en las sociedades de control: prácticas de resistencia de estudiantes y regulación de las conductas en escuelas secundarias en contextos de pobreza urbana del Partido de San Martín. Tesis doctoral de la Universidad de Buenos Aires, Facultad de Filosofía y Letras: Buenos Aires.

- Lazzarato, M. (2006). Políticas del acontecimiento. Buenos Aires: Tinta Limón.

- $\quad$ Nietszche, F. (1980). La voluntad de poderío. Madrid: EDAF.

- Perea Acevedo, A. J. (2009). Estética de la existencia. Las prácticas de sí como ejercicio de libertad, poder y resistencia en Michel Foucault. Bogotá, Colombia: Impreso por autor.

- Ratier, H. (1972). Villeros y villas miseria. Buenos Aires: Centro Editor de América Latina.

- Reguillo, R. (2012). Culturas juveniles. Formas políticas del desencanto. Buenos Aires: Siglo veintiuno editores.

- Rockwell, E. (2006). "Los niños en los intersticios de la cotidianeidad escolar: ¿resistencia, apropiación o subversión?". En Conferencia presentada en el XI Simposio Interamericano de Etnografía de la Educación Buenos Aires, 2006.

- Scott, J. (2000). Los dominados y el arte de la resistencia. Discursos ocultos. México: Ediciones Era.

- Sennett, R. (2009). El respeto. Sobre la dignidad del hombre en un mundo de desigualdad. Barcelona: Anagrama. 